\title{
Social marketing: an overview of approach and effects
}

\author{
W A Smith
}

Injury Prevention 2006;12(Suppl I):i38-i43. doi: 10.1136/ip.2006.012864

Correspondence to: W A Smith, Executive Vice President, Academy for Educational Development, 1825 Connecticut Ave., NW, Washington, DC 20009, USA; bsmith@aed. org

Accepted 27 April 2006
This paper reviews the applicability of commercial and social marketing to teen driving safety. It draws on a wide range of information, including evaluation studies of specific programs as well as standards of practice within these two professions. Social marketing has been widely applied for more than three decades in the fields of public health, environmental protection, and political marketing with significant success. The paper attempts to distinguish between the practice of commercial marketing, whose goal is profit, and the practice of social marketing, whose goal is societal benefit. Issues of sustainability, segmentation, differences in behavioral characteristics, and cultural competence are discussed with specific examples drawn from the transportation safety literature. The paper suggests that social marketing represents a viable companion to control and education approaches to behavior change to promote teen driving safety.
S ocial marketing is not a science, but rather a professional craft which relies on multiple scientific disciplines to create programs designed to influence human behavior on a large scale. Commercial marketing targets purchase behaviors, product choice behaviors, and product promotion behaviors. People are asked to buy products, switch brands, and talk favorably about a company's product. Social marketing typically targets complex, often socially controversial behaviors, with delayed and distant benefits to audiences who often do not recognize they have a problem, much less are looking for a solution. Like other professional crafts (that is, clinical medicine) marketing uses science extensively, but it is also learned through experience. It is a flexible framework within which scientists, managers, and artists work together to influence behavior on a massive scale.

Social marketing has been in the marketing literature since the 1960s. Variations of social marketing have been applied to promote traffic safety, tobacco control, drug prevention, childhood immunizations, improved nutrition and diet, and environmental behavior, as well as to reduce infant mortality.

\section{EFFECTS OF SOCIAL MARKETING PROGRAMS}

The overall percentage of increased seat belt use in the United States was due to the widespread availability of seat belts, publicity from organizations like Mothers Against Drunk Driving (MADD), and stronger seat belt laws. ${ }^{1}$ Click it or ticket, a program that demonstrated the importance of primary seat belt laws combined with effective publicity of enforcement, increased seat belt use in North Carolina from 63\% to $80 \%$ and went on to become a national model. ${ }^{2}$

Zero tolerance means zero chances, a social communication campaign, found awareness of the no tolerance law rose from $61 \%$ to $63 \%$ over six months.

Friends don't let friends drive drunk, a social advertising campaign of the Ad Council, reported an $85 \%$ recall of the messages. In addition, $80 \%$ of those reported they took action to stop a friend from driving and $25 \%$ said they stopped a friend from driving while intoxicated. ${ }^{4}$

Social norming programs such as Montana's "2 out of 3" reported a slight reduction in impaired driving by university teens. Other social norming programs showed effects in multiple university settings in reducing alcohol abuse among college age students-Florida State University reported a 15\% reduction in high risk drinking among male students and 5\% among females; Hobart and William Smith Colleges in New York reported a $32 \%$ reduction in student athletes drinking more than once per week. ${ }^{5}$

Florida's first TRUTH anti-smoking campaign, which reduced teen smoking in one year by $19 \%$, was also followed by a well funded national campaign. ${ }^{6}$

The Centers for Disease Control and Prevention's VERB campaign, which promoted activity among teens 9-13, reported a $74 \%$ national awareness of the campaign after one year.

Dozens of HIV/AIDS prevention efforts ranging from the Swiss Stop AIDS Program, which increased condom use in casual partners from $50 \%$ to $80 \%$, to programs throughout the developing world in Uganda, Jamaica, Brazil, Thailand, etc, have also shown positive results. ${ }^{8}$

PREMI, a program in Ecuador, increased full immunization coverage of the highest risk infants at one year of age from $5 \%$ to $28 \%$ in 18 months. ${ }^{9}$

Mass media and health practices, a program in Honduras, increased correct use of oral rehydration solution from 9.2\% to $44.8 \%$ in five years. ${ }^{10}$

Exclusive breastfeeding rates were increased in Madagascar from $46 \%$ to $68 \%$; in Ghana from $68 \%$ to $79 \%$; and in Bolivia from $54 \%$ to $65 \% .^{11}$

Dozens of family planning programs throughout the world have increased contraceptive use in resistant rural populations of complex and multicultural backgrounds. ${ }^{12}$

Unsuccessful social marketing programs are also well documented. They include high profile programs such as the US National Anti-Drug Campaign of the late 1990s, the early anti-smoking campaigns, as well as numerous other programs throughout the world. The US Got milk? campaign demonstrated the difficulties of effecting widespread behavior change. The \$110 million ad campaign ran over five years and showed no corresponding increase in milk sales. Changes in milk packaging and flavoring caused a modest increase, but competition from the booming bottled water industry and a price increase for raw milk caused those increases to eventually disappear. Social marketing is a continuous struggle against unpredictable competing forces.

All of the specific evaluation data presented above have been submitted to peer review. Weaknesses in the studies include many of the difficulties associated with measuring large scale behavior change. Some studies have appeared to accelerate secular trends, while others have conflicting causal 
explanations. However, all of these studies figure as important research in the social marketing, transportation, and public health literature. In addition to these few programs, hundreds of other social marketing and thousands of commercial marketing programs have been analyzed in the professional marketing literature. The findings cited here represent standards of practice for that profession and recognize that marketing is both art and science.

\section{UNINTENDED EFFECTS}

Because social marketing is a "scaled up" intervention, which often uses mass media to carry messages, unintended effects have been documented. ${ }^{13}$ In the Philippines, an HIV/AIDS program designed to debunk the myth that mosquitoes carry HIV had the unintended consequence of reducing empathy for HIV+ individuals. The public reasoning was that "one cannot be blamed for mosquito behavior, but people can be blamed for their own sexual activity". Unintended effects have only rarely been studied, but represent a legitimate area of concern to social marketers. Hypothetically, the unintended consequences of media ads which teach parents how to talk to teens about driving might also give teens, who see the ads, counterarguments.

BACKGROUND OF SOCIAL MARKETING APPROACH The social marketing definition illustrates five key elements of the approach:

- a program management process (sequenced action steps);

- designed to influence human behavior on a large scale;

- by creating benefits and reducing barriers that matter to specific audiences;

- through consumer oriented decision making (audience behavior is key);

- leading to increased societal benefit (as defined by somebody).

Social marketing is characterized by nine fundamental principles:

1. The Marketing Mix is the primary element that differentiates social marketing from communication and advertising approaches with which it is often confused. When Coca Cola markets a new drink it must first design the product's color, taste, and consistency. It then prices that product to be competitive, places or distributes that product in places where people are most likely to desire it, and then they promote it, using a wide variety of approaches including prizes, events, publicity, advertising, and discounts. In social marketing, however, the product is often the desired behavior itself ("breastfeed your child at work") and/or some supporting device or policy necessary to make the behavior possible (a breastfeeding room in a modern office complex); price is the embarrassment and time required to breastfeed, while promotion is all the activities the company and coworkers take to reduce the embarrassment and support the behavior. 2. Let's Make a Deal. Perhaps social marketing's principal contribution to social change is the notion that voluntary human behavior is achieved through an exchange of value. It argues that people change not only because they are well informed or forced into action, but also because they get something they value in return. The process of behavior change in social marketing attempts to reduce the cost and increase the benefits of the new behavior.

3. Change conditions before messages. Behavior is tough to change. Don't do it if you don't have to. If you can create a safer air bag, why worry about seat belts? Also, consider conditions that make adoption difficult, such as social justice, barriers due to poverty, discrimination, and poor access to services. A parent oriented program, for example, might have to address the limited time that working Hispanic parents have with teens, or the language barriers which the teen, as the most proficient English speaker in the family, may overcome while his or her parents may struggle. The most powerful marketing question you can answer is: What can I do to make it unnecessary for my audience to change their behavior and still achieve my social goal?

4. It's about behavior, not awareness. Three characteristics of social marketing behavior are:

- observable action by a specific ...

- segment of the population, under specific ...

- conditions

Example: men between the ages of 17 and 20 will buckle up before placing the car in gear when driving a passenger vehicle.

A call to action is the centerpiece of a social marketing campaign. People want to know what to do, not what to think. Social marketing is skeptical of the notion that information leads to behavior change-although we recognize that in the case of a highly salient consequence (infant death), an information campaign on SIDS which promotes a simple but effective behavior (place the infant on his/her back to sleep and avoid Sudden Infant Death Syndrome), there is convincing evidence that information alone can effect large scale behavior.

Figure l describes two examples of similar behaviors, performed by different segments, under different conditions. This analysis is helpful in determining interventions that will be effective under various conditions.

Behaviors

What is behavior?

\begin{tabular}{l|l|l} 
Action & $\begin{array}{l}\text { Put child in back } \\
\text { seat }\end{array}$ & $\begin{array}{l}\text { Put child in back } \\
\text { seat with appropriate } \\
\text { restraints }\end{array}$ \\
\hline Segment & $\begin{array}{l}\text { Mother of two } \\
\text { children; aged 12 } \\
\text { and 7 }\end{array}$ & $\begin{array}{l}\text { Father of one } \\
\text { child age 6 }\end{array}$ \\
\hline Condition & $\begin{array}{l}\text { When driving the } \\
\text { family van with four } \\
\text { other children in it }\end{array}$ & $\begin{array}{l}\text { On the way to } \\
\text { preschool }\end{array}$ \\
\hline
\end{tabular}

Figure 1 Example of analysis of behavior useful in determining effectiveness of interventions under varying conditions.

5. Mine is better than his. People have choices. Therefore, almost all behaviors compete with other behaviors to provide benefit to the individual. Coke competes with Pepsi; condom use among teens competes with the fear of "losing an erection if I use a condom", and driving safely competes with "I have to take this cell phone call, it's from my date". Any benefits we offer to "drive carefully" must not only be appealing to the individual teen, but must also compete effectively with benefits offered by alternative behaviors.

6. The audience is always right. Consumer and market research is at the heart of all effective social marketing. In addition to asking why people engage in a specific behavior, market research is focused on the answers to a series of practical questions leading to program design decisions, questions such as: 
- How are people different so that we can target their specific wants?

- What benefits do people care about most?

- Where are people most likely to want to go to get our products and services?

- What barriers are the toughest for people to deal with, and how can those barriers be lowered?

- How important is the "price" of a new behavior to different users?

- What messages (language, metaphors, images) break through the clutter of other messages and resonate as authentic for them?

7. What do they have in common? While all people and communities are different from each other, they can be grouped into segments that maximize our ability to influence their behavior. An audience segment is a group of individuals who share a set of common characteristics. These characteristics include:

- Demographics - the same age, income, gender, or ethnic range.

- Risk factors, which differentiate high and low risk audiences (people who refuse to buckle up).

- How they engage in the risk behavior (they don't buckle up until they reach the first traffic light).

- Wants-they desire the same basic goal in performing the risk behavior (they want to get a fast start).

- Perceptions-they share attitudes about the behavior ("fast start makes me feel like a race car driver").

- Channels-they share the same channels of communication and look to the same spokespersons as credible ("I'll listen to my kids, but not my wife. She nags about everything").

- Readiness to change ("I've been trying to use my seat belt, but I just keep forgetting" versus "I am never going to use that darn thing, it's a nuisance").

- Often a segment will be based on a combination of these factors.
There are three aspects of a target segment that make it more viable:

1. Does their behavior contribute to solving the problem?

2. Is the segment large enough to make a measurable difference?

3. Is the segment small enough for us to reach effectively with our resources?

8. Behaviors are different-marketing adjusts to the differences. Some behaviors are simple: place an infant on its back to sleep in order to prevent SIDS. Some behaviors are natural but under strong external attack: breastfeed an infant for a full six months. Some behaviors are politically sensitive (needle exchange to prevent HIV transmission, abortion, sex education in school). Some behaviors are supported by strong enforcement policies (seat belt use, drunk driving, hand gun use). Others are complex and require new skills, such as the management of infant diarrhea in an African village. Some behaviors are well understood, while others are novel and seem curious. Some behaviors have naturally occurring rewards, while others have delayed rewards, or no rewards that an audience cares about. Each of these factors and more are critical points in understanding which marketing strategy is needed (fig 2).

Figure 2 defines four common dimensions and four specific teen driving variations. Research on the differences between these behaviors is useful in choosing an appropriate marketing strategy.

9. Involvement. This principle considers the importance of the audience's active participation and shared control over the design and execution of specific activities.

\section{Social marketing measurement framework}

Figure 3 is a logic framework that illustrates the variables marketers consider important in establishing the success of a social marketing effort.

In sum, social marketing is a flexible, eclectic practice of large scale social change. It is a way of thinking that places emphasis on an "exchange of value" with the audience rather than social control or education alone.

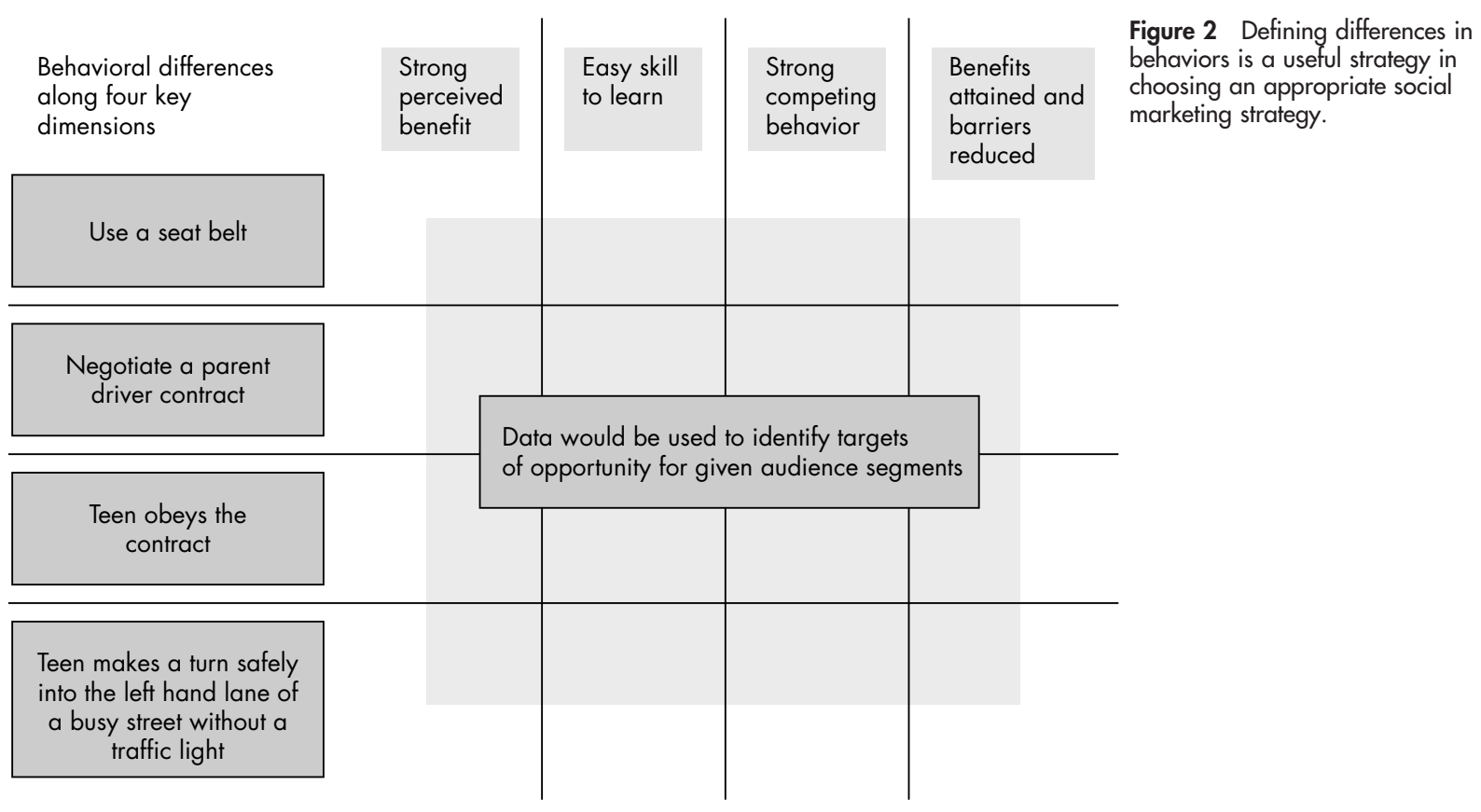




\section{SPECIAL ISSUES IN TEEN DRIVING AND SOCIAL MARKETING \\ Lessons from commercial marketing to teens}

In 2004 in the US teens spent $\$ 105$ billion and influenced another $\$ 48$ billion. In 1998 US companies spent $\$ 200$ billion on advertising. Teens are exposed to 3000 ads a day. Eighty three percent of teens reported going online in $2004 .{ }^{14}$ Teens are a priority market for commercial marketing in America today, and tens of millions of dollars are invested in teen research. Here are some of the beliefs about teens that emerge from that experience.

- Teens change rapidly, and therefore correct segmentation by age is essential.

- Teen opinions are very strong and they want to be listened to, not talked at.

- Rebellion and independence from authority is a strong motivator.

- Embedding messages in other content is better than straightforward, hard sells.

- Social networks may be more important than generalized "coolness".

- Brands are important—a brand represents something they come to trust.

Children develop brand loyalty by age 10, and fix brand loyalty by age 15. Their preferred "space" is bedrooms or dens. Teen segments are typically defined by readiness to change: innovators $(2-3 \%)$, trendsetters $(7 \%)$, early adopters $(10 \%)$, and mainstream $(80 \%)$. It is generally agreed that fads pass down through this segmentation strata. Most marketing data is on younger teens, but maturation changes between 13 and 19 are huge. The key seems to be segmentation based on beliefs specific to age groups. ${ }^{13}$

\section{Marketing approaches to teen research}

Focus groups are woefully inadequate as a means to understand any audience, but given the rapid changes in teen attitudes and the impact of peer influence, they are particularly inadequate. A wide variety of alternative research tools have emerged, including: ethnographies; small panels during which teens are given assignments and tracked over time; immersion hikes, where research is embedded in day-long activities; computer assisted telephone focus groups; and "up to fives", where clients can listen in to telephone interviews with up to five respondents and direct cueing questions to interviewers secretly. Doer/non-doer studies compare trendsetters and early adopter segments to identify determinants that predict behavior. Room shopping gets permission from teens to search their rooms to identify the variety of items that may be used for motivational purposes. There are a plethora of information and information systems directed at understanding youth. One interesting system is called TRU, Teenage Research Unlimited. They provide an updated subscription service based on a 2000 plus, nationally representative survey of 12-19 year olds in six-month waves on the behavior and changing motivational attitudes of US teens.

\section{Cultural competence, social marketing, and teen driving}

Culture in America is often synonymous with ethnicity, but in marketing there can be a culture of risk takers, a culture of pick-up truck drivers, a culture of men drivers, and a culture of women drivers. Many of these cultures can be cross referenced, so you should have a culture or segment of female teen drivers who take risks. Justification for the importance of these cultures is reflected in a few statistical facts:

Among adults ages 65 and over, motor vehicle injury rates are twice as high for men than for women. Male high school students are less likely than female students to wear seat belts. ${ }^{15}$ African American high school students are less likely than white students to wear seat belts all the time, putting them at increased risk of motor vehicle related injuries. ${ }^{16}$ Among Hispanic Americans pedestrian fatalities are nearly twice as high as for whites. The Hispanic population makes $50 \%$ more walking trips than non-Hispanic populations. ${ }^{17}$

These behavioral differences are often accounted for by belief systems called cultures, as well as external factors such as car ownership, economic status, or education level. A marketing plan developed by the Louisiana State TIGER program used market research to define the differences between key traffic safety segments. For example, the program reports that community messages rather than individual messages work best with the Hispanic population. Humor is less likely to be effective. In African American communities demonstrating respect for the individual is key.

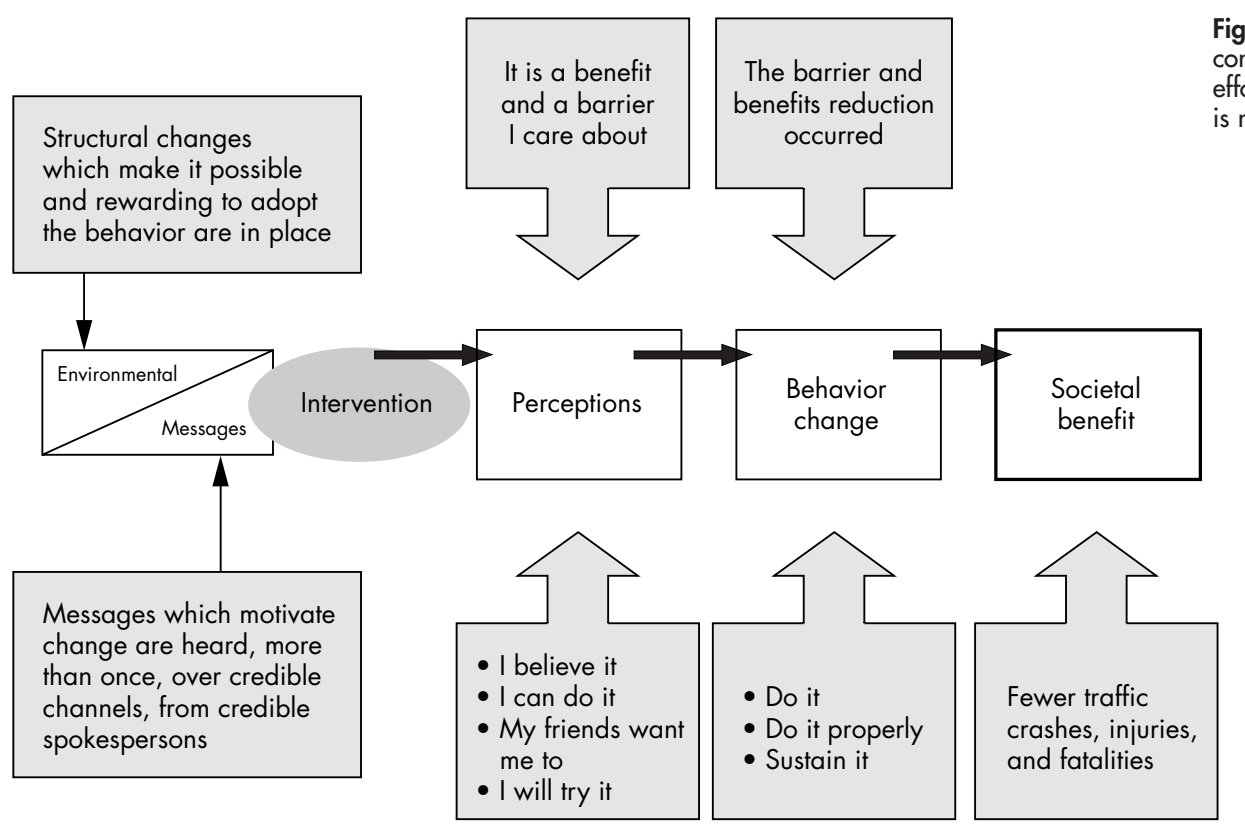

Figure 3 Logic framework useful in conceptualizing social marketing efforts. The gray boxes list evidence that is most often measured. 
Hypothetical social marketing strategy

\section{PROBLEM STATEMENT}

1. What is the social problem I want to address? Reduce the number and severity of automobile crashes.

\section{BEHAVIOR}

Objective: 2. What action do I believe will best address that problem?

Reduce the number of unlicensed teens who are driving a car by $70 \%$.

\author{
Audience: 3 . Who is being asked to take that \\ action: \\ - Unlicensed teen drivers \\ - Their parents \\ - State legislators \\ - Traffic enforcement officers
}

\section{OVERALL STRATEGIC OPTIONS}

1. Understand the behavior of parents better Look for structural differences in families, identify who influences both groups' decision making, and identify perceived barriers and benefits to both behaviors.

\section{Re-frame the problem}

Make legislators aware of new data on the large number of unlicensed teens driving automobiles. Change the "framing" of the problem from drunk driving to illegal driving. Pose the question: what are these parents thinking?

\section{Identify specific behaviors that will help parents change}

Identify specific parent behaviors that could be brought under enforcement control.

\section{Energize the police sales force}

Use police networks to promote enforcement of existing laws. Look for ways to make the new enforcement compatible with existing Click it or ticket approaches.

5. Create a large scale behavioral media campaign directed at parents, teens, enforcement, and legislators

Publicize the strategy that was selected from among alternatives $1-4$.

With the Indian population cooperation is highly valued and being quiet and still is a valued behavior. For so-called $\mathrm{Y}$ generation teens honesty, trustworthiness, and sincerity are valued. These generalizations are useful starting points for targeted marketed research with specific population under specific conditions. ${ }^{18}$

\section{Sustainability of social marketing programs}

Have you ever heard of a product called Coca Cola? If your answer is yes, as it is for billions of people around the world, then why does Coca Cola keep marketing? Why does it continue to change its container, offer price specials, invent new products, and advertise?

There are a few social behaviors, such as using a seat belt, that remain constant over a long period of time, that are easy

\section{About the author}

William A Smith is the Executive Vice President of the Academy for Educational Development (AED). He is also a co-founder of the Social Marketing Institute, a columnist and editorial board member of Social Marketing Quarterly, the International Journal of Health Communication, and Applied Environmental Education and Communication: An International Journal. He recently received the Alan Andreasen Award for scholarship and practice in Social Marketing and served on the IOM committee on health literacy. Dr Smith has a doctoral degree from the University of Massachusetts in non-formal education with an emphasis on gaming theory and an Honorary Doctorate in Science from the University of South Florida. The AED is an independent, non-profit organization that works to foster large scale social change in education, health, and the environment, and is committed to solving critical social problems and building the capacity of individuals, communities, and institutions to become more self-sufficient.

to execute, and that become part of the driving experience. These can be said to be sustainable, as long as a dramatic new event does not occur. Remember we once thought that breast self-examination was the best way for women to detect breast cancer early; then our science changed. In social marketing the cost of marketing has to be built into the cost of programs. The level of marketing costs often varies over the lifetime of a behavior or product. Launch and introduction are often the most expensive, maintenance can cost less, and reviving an old idea can cost somewhere in between.

\section{Thinking like a marketer: a hypothetical case study}

A social marketing strategy provides both a way to think about a problem and a blueprint for action. The strategy shown in the box at left is totally hypothetical.

\section{CONCLUDING REMARKS}

This paper demonstrates the effectiveness and limitation of social materials in addressing large scale behavior change. Traffic safety programs such as Click it or ticket have already used social marketing successfully as an organization model. It suggests that commercial market research on teens could be of value to the safe driving community.

\section{ACKNOWLEDGEMENTS}

This paper was first presented as part of the first Expert Panel meeting of the Youthful Driver Research Initiative, a collaborative research program between the Center for Injury Research and Prevention (http://www.chop.edu/injury) at the Children's Hospital of Philadelphia (CHOP) (http://www.chop.edu) and State Farm Insurance Companies ${ }^{\circledR}$ (State Farm) (http://www.statefarm.com). The views presented in this paper are those of the author(s) and are not necessarily the views of CHOP or State Farm.

\section{REFERENCES}

1 Williams AF, Wells JK, Reinfurt DW. Increasing seat belt use in North Carolina. In: Hornik RC (ed). Public health communication: evidence for behavior change. Mahwah, NJ: Lawrence Erlbaum Associates, Publishers, 2002:85-96.

2 National Highway Transportation Safety Administration. Click It or Ticket in North Carolina: a case study of a successful campaign to raise the seat belt use rate. 2004 Available at http://www.nhtsa.dot.gov/people/injury/airbags/ BucklePlan/BUA_WEBSITE/Archive-04/Cases/NorthCarolina.html (accessed April 2006).

3 The Robert Wood Johnson Foundation. 'Zero Tolerance Means Zero Chances' is favored slogan for teen drunk driving campaign. Grant Results Report. 2000. Available at http://www.rwjf.org/reports/grr/032694s.htm (accessed April 2006).

4 National Highway Transportation Safety Administration. Designated Driver Safe Ride Program. DOT HS 809 148. Available at http:// 
www.nhtsa.dot.gov/people/injury/alcohol/DesignatedDriver/introl .html (accessed April 2006).

5 Hanson DJ. Social norms marketing is highly effective. Potsdam, NY: State University of New York, http://www2.potsdam.edu/hansondj/Youthlssues/ 1093546144.html (accessed April 2006).

6 Zucker D, Hopkins RS, Sly DF, et al. Florida's "truth" campaign: a countermarketing, anti-tobacco media campaign. J Public Health Manag Pract 2000;6:1-6

7 Huhman M, Potter LD, Wong FL, et al. Effects of a mass media campaign to increase physical activity among children: year-1 results of the VERB Campaign. Pediatrics 2005; 116:e277-e284.

8 Wellings K. Evaluating AIDS public education in Europe: a cross-national comparison. In: Hornik RC (ed). Public health communication: evidence for behavior change. Mahwah, NJ: Lawrence Erlbaum Associates, Publishers, 2002:131-46

9 Seidel R. Results \& Realities: A decade of experience in communication for child survival. Figure 3. Washington, DC: HALTHCOM Project, Academy for Educational Development, 14-15.

10 Seidel R. Results \& Realities: A decade of experience in communication for child survival. Figure 7. Washington, DC: HALTHCOM Project, Academy for Educational Development, 21.
11 Quinn VJ, Guyon AB, Schubert JW, et al. Improving practices on a broad scale at the community level: success stories from Africa and Latin America. $J$ Hum Lact 2005;21:345-54.

12 Harvey PD. Let every child be wanted: how social marketing is revolutionizing contraceptive use around the world. Westport, CT: Auburn House, 1999.

13 Buchanan DR, Reddy S, Hossain Z. Social marketing-a critical appraisal. Health Promot Int 1994;9:49-57.

14 FRONTLINE. The Merchants of Cool: A Report on the Creators \& Marketers of Popular Culture for Teenagers. PBS: 2005, Available at http://www.pbs.org/ wgbh/pages/frontline/shows/cool/ (accessed April 2006)

15 Williams AF, McCartt AT, Geary L. Seatbelt use by high school students. Inj Prev 2003;9:25-8.

16 Briggs NC, Levine RS, Haliburton WP, et al. The Fatality Analysis Reporting System as a tool for investigating racial and ethnic determinants of motor vehicle crash fatalities. Accid Anal Prev 2005;37:641-9.

17 Centers for Disease Control and Prevention. Injury Fact Book 2001-2002. Different People, Different Injuries. Available at http://www.cdc.gov/ncipc/ fact_book/07_Different.htm (accessed April 2006).

18 Louisiana Department of Public Safety. Lovisiana Occupant Protection Marketing Plan for at-risk populations. Available at http:// www.dps.state.la.us/tiger/marketing.html (accessed April 2006). 